\title{
Science lessons
}

\section{Japan must learn from its mistakes in the human genome project.}

\section{Genomu Haiboku (A Defeat in the Genome Project) \\ by Nobuhito Kishi \\ Diamond: 2004. 374 pp. $¥ 2,100$. In Japanese. \\ Yoshiaki Ito}

In the 1970s, a leading Japanese scientist, Akiyoshi Wada, pioneered the idea of developing technology to allow the rapid sequencing of DNA. Yet when the human genome sequence was published in 2001, Japanese scientists had contributed just $6 \%$ of it, compared with $59 \%$ in the United States and $31 \%$ in Britain. In Genomu Haiboku, journalist Nobuhito Kishi examines the reasons why.

The book follows Wada's career, much of it spent at the University of Tokyo. In 1975 he had the idea for an automated rapid DNAsequencing machine, and in 1979 he tried to establish a project to build one. But the plan was resisted by both academics and bureaucrats, and it was not until 1981 that he won government approval to head a national project to develop the machine. Wada was considered eccentric and had difficult relationships with both fellow scientists and bureaucrats, who didn't have the foresight to appreciate his idea, and in 1989 he was removed from the project he had conceived.

Two other Japanese scientists also invented technologies that were critical to the success of the Human Genome Project. One was Yuzuru Fushimi, whose four-colour fluorescence dyeing of nucleotides was an enormous advance over traditional methods. His patent application was rejected, however, because he was supported by government grants, which meant that the intellectual property belonged to the government. The second, Hideki Kambara of Hitachi, and independently Norm Dovichi of Canada - described as "unsung heroes" of the genome project by Science - invented a DNA analysis device using multicapillary arrays. It was Kambara's sheath-flow method, in combination with fluorescence labelling developed by Perkin Elmer, that was used in the fast sequencing machines made by Applied Biosystems $(\mathrm{ABI})$, which allowed the rapid completion of the human genome sequence.

Wada's leadership of the Japanese project to develop an automated DNA sequencing machine coincided with a trade war between Japan and the United States. His initiative was caught in the middle, and his proposal to mechanize DNA sequencing was considered by US scientists to be a threat from the technologically superior Japan. In fact, the first commercial DNA sequencing machine, based on Leroy Hood's four-colour

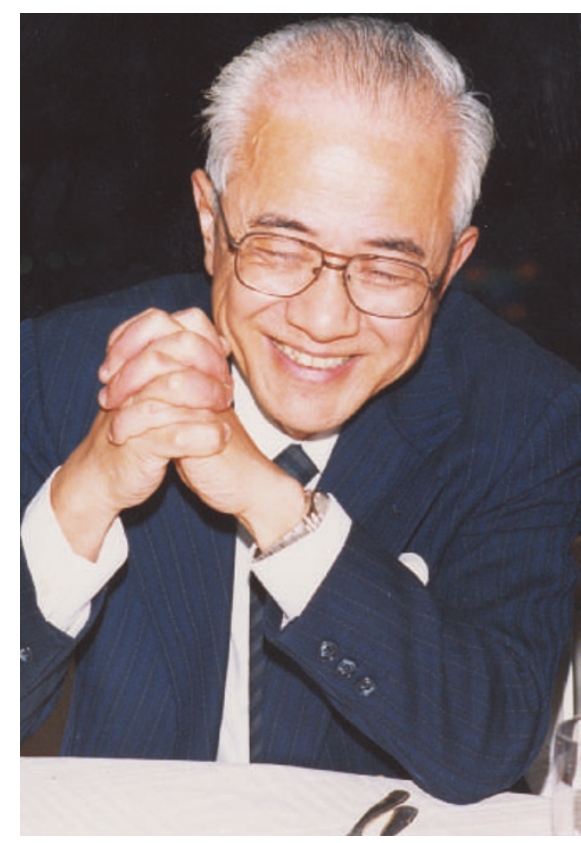

Japan failed to capitalize on Akiyoshi Wada's success in pioneering DNA sequencing machines.

fluorescence labelling method, was manufactured by ABI in 1986.

As the project to sequence the human genome gathered momentum in the United States, James Watson initially sought funding from Japan, with international collaboration in mind. Eventually, Watson obtained the necessary funds from the US government - the United States spent $\$ 2.7$ billion on the genome project, compared with just $\$ 120$ million in Japan. The reaction of the Japanese bureaucrats was, typically, "too little, too late”, which apparently infuriated Watson.

In Genomu Haiboku, Kishi describes how the organization and traditions of the Japanese scientific community inhibit the development and growth of new concepts. For example, there is no decision-making body for strategic national science policy. Administrative structures are divided vertically, so bureaucrats work within their own limited territory, and the power structure of a scientific community is made up in such a way that scientists tend to defend their own vested interests. In addition, Japan is often said to make major changes only when forced to by gaiatsu, or foreign pressure.

Kishi asks whether the situation has since improved. The second half of the book describes current scientific activities in Japan in the post-genome era, such as the Protein 3,000 project to determine the three-dimensional structure of 3,000 proteins, and the establishment of a mouse genome encyclopaedia expected to contain full-length complementary DNA for all mouse genes. There are new breeds of scientist and businessman who may influence Japan to become more competitive yet more down-to-earth.

What should Japan learn from its 'defeat' in genome sequencing? Kishi points out the weaknesses built into Japanese society, and prompts readers to think about concrete measures that Japan could take to adapt more quickly and flexibly to change, increasing its competitiveness. The author touches on elements of Japanese culture that discourage innovation and creativity.

Wada was said to be odd, but so are many creative people. Craig Venter, who revolutionized DNA sequencing strategy and helped to bring genome sequencing years ahead of the mandate set by the US National Institutes of Health, is considered by some to be a heretic - but he is widely acclaimed in the United States. I believe that Japan must overcome its traditional conservatism and learn to tolerate and value this type of individualistic mind. Time and time again, creative people and their achievements are noted and appreciated by their fellow Japanese only after the Western world has lauded them. Recently, attempts have been made to improve these shortcomings. For example, the Japanese Council for Science and Technology Policy, Cabinet Office, was created to oversee the country's science and technology policies. Measures initiated to protect intellectual property are also taking effect.

When the genome project was first proposed, there was strong opposition in both the United States and Japan. In the United States, dissenters were soon in the minority, perhaps partly because of Watson's strong leadership, but they persisted for much longer in Japan. Japan is not alone in being wary of taking risks, and no good would come from blaming government bureaucrats for being overly cautious. But there is surely a pressing need to increase the number of scientists in government administration. This raises the question of how academic societies should evolve to become more open and responsive to new developments in the field, while being more accountable for the nation.

I have often witnessed most of the Japanese scientific community voicing objections simply to protect their vested interests when funding for a new research area is proposed. However, once bureaucrats or politicians realize the importance of a new proposal and take action to create a funding scheme, researchers become much more supportive. What happens next is always the same, regardless of the project or people involved. 
The status quo is maintained. The age-old power structure, involving scientific communities and bureaucrats, is retained, and those in power continue to control the distribution of funds. The personnel change, but their successors are always chosen from people who conform to this tradition. This basic structure has never really altered.

How can it be changed? Ryoji Noyori, Nobel laureate and president of RIKEN, the Institute of Physical and Chemical Research, believes that Japanese graduate education must be restructured to produce better young scientists who can work independently and who are able to interact with other scientists both in Japan and abroad. Accepting more young, foreign scientists in Japanese educational and research institutions would also make Japan more open and international.

The theme of the book is that Japan must become more competitive. Kishi describes many faults in the Japanese system and persuades the reader of their validity. He warns eloquently that Japan's survival depends on the accumulation of intellectual property to build a nation based on science and technology. However, scientific knowledge should be shared by everyone, and the book does not address the need to temper international competitiveness to foster international cooperation rather than confrontation. The role that Japan should play in the global arena, and especially in Asia, is also neglected. But despite these criticisms, it is certain that this book will have a great effect on the Japanese scientific community.

Yoshiaki Ito is at the Institute of Molecular and Cell Biology, Singapore, and is director of the Oncology Research Institute, National University of Singapore, 61 Biopolis Drive, Proteos 138673, Singapore.

\section{Positive thinking}

Exuberance: The Passion for Life by Kay Redfield Jamison

Alfred Knopf: 2004. 416 pp. \$24.95

\section{Daniel Nettle}

What quality is shared by the great innovators and leaders in science, arts and public life? What characteristic is common to such restless and inspirational figures as Theodore Roosevelt, Richard Feynman, Humphry Davy and James Watson, the codiscover of DNA? Jamison believes that there is a common thread in these disparate psyches, and she calls it 'exuberance'. She describes this as an intersection of various different capacities: boundless optimism, energy, an ability to captivate others, a sense of joy, and a continuation into adulthood of the child's capacity for wonder and play.

Readers may be familiar with Jamison's memorable previous books, on bipolar disorder (Touched with Fire) and suicide (Night Falls Fast), and her memoir (An Unquiet Mind). This latest book, Exuberance, draws as ever on a wide range of biographical and literary, as well as scientific, material. The link with her work as a psychiatrist is also clear, as the positive attributes of exuberance — energy, restlessness and optimism — can easily tip over into the pathology of clinical mania. Moreover, the highly exuberant are often prone to intermittent bouts of deep depression. Here, as in Touched with Fire, one is reminded that, as Dryden put it: "Great wits sure are to madness near allied/ And thin partitions do their bounds divide."

Jamison writes poetically, as ever, and many of the portraits and literary examples

\section{Museum collection}

\section{A taste of their own medicines}

It became a tradition at the University of Florence's Institute of Pharmacology and Toxicology to assemble all manner of drugs and medicines. After all, reasoned the institute's directors, you never know when a researcher might become interested in a particular therapeutic group.

The hoard has recently been recognized as a collection of considerable historic interest, and much of it has now been catalogued by Piero Dolara and Graziana Fiorini, researchers at the Italian institute.

The catalogue, which has been written in both Italian and English, is available from Firenze University Press and online at http://digital.casalini.it/8884532183. It describes the drugs and provides a short history of experimental pharmacology.

The collection comprises more than 600 hand-blown glass jars from around the world, containing, for example, some rare Arabic

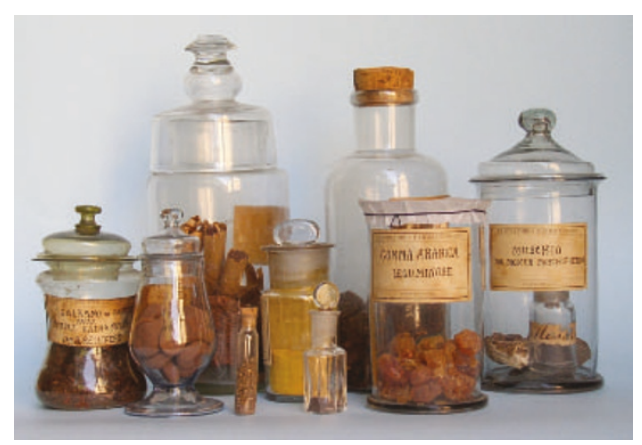

preparations made from medicinal plants. Most of the drugs in the collection are from botanical sources. Several, such as quinine, digitalis, aspirin, morphine and cocaine, are still in use.

But the catalogue throws out a caution to romantics who prefer the concept of 'natural' medicine to synthetic pharmaceuticals. Many of the botanical preparations would have been ineffective, or toxic, it notes.

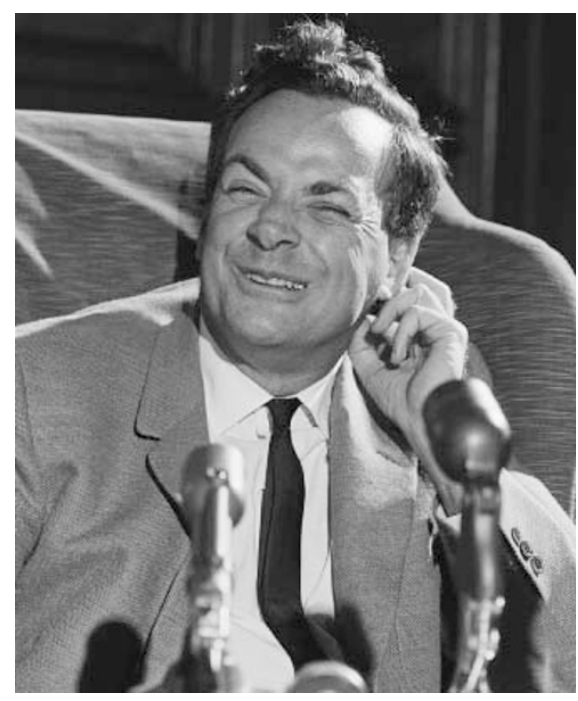

Up to scratch: the exuberant Richard Feynman.

are highly engaging. But I must confess that the book seemed to me to be limited by its lack of a strong underlying thesis. Jamison relies on the rather old-fashioned idea that emotions basically come in two types: negative ones, such as fear, worry and sadness; and positive ones, such as joy, enthusiasm, wonder, and so on. Exuberance then becomes simply having the capacity for all the positive emotions in ample dose. Psychologists no longer view emotions in this way, however. Emotion systems are probably better seen as discrete mental programmes, each with different design features and content. Fear is quite different from anger, even though both are negative, and it would be possible for someone to be temperamentally high on one but not the other. Similarly, joy is quite different from, for example, ambition, desire or openness to experience. At one point, Jamison says that happiness is a dilute version of exuberance, but it is far from clear that this is the case, because great innovators are often driven by dissatisfaction rather than well-being.

Jamison lumps all emotions that either feel positive or that she judges to have positive effects into one category, so we are left with an undifferentiated view of what really typifies the exuberant individuals of her study. Often it may be the combination of extraversion, which accounts for the ambition and socially captivating behaviour, and neuroticism, which keeps them worrying away at problems for so many years and leaves them vulnerable to depression. In truth, it could be that there is no single psychological trait common to all the highly diverse figures profiled in the book.

A much deeper problem is that Jamison is impartial, almost hectoring at times, as she evangelizes the many benefits of exuberance (though, to be fair, there is one chapter on the drawbacks). She believes the trait to be genetically based, and strongly advantageous, so one naturally wonders why exuberant 